\title{
Dependence of Magnetic Properties with Structural/Microstructural Parameters of Ball-milled Fe15Co2P3 Powder Mixture
}

Hanane BERKANI

Eltarf University

Rachid SIAB

Eltarf University

Wassila TEBIB ( $\sim$ wassilmss@yahoo.fr)

University Eltarf https://orcid.org/0000-0002-8593-5598

Locif REDOUANI

Eltarf University

Saida BOUKEFFA

Eltarf University

Mohamed BOUOUDINA

University of Bahrain

\section{Research Article}

Keywords: Fe15Co2P3, Ball milling, XRD, Rietveld, Mechanical, Magnetic

Posted Date: July 7th, 2021

DOI: https://doi.org/10.21203/rs.3.rs-672671/v1

License: (1) This work is licensed under a Creative Commons Attribution 4.0 International License. Read Full License

Version of Record: A version of this preprint was published at The International Journal of Advanced Manufacturing Technology on December 2nd, 2021. See the published version at https://doi.org/10.1007/s00170-021-08397-1. 


\title{
LETTER TO THE EDITOR
}

\section{Dependence of Magnetic Properties with Structural/Microstructural Parameters of Ball-milled Fe15Co2 $P_{3}$ Powder Mixture}

\author{
Hanane Berkani ${ }^{1, .2}$, Rachid Siab ${ }^{1}$, Wassila Tebib ${ }^{1, \bowtie}$, Locif Redouani ${ }^{1}$, Saida Boukeffa ${ }^{1}$, \\ Mohamed Bououdina ${ }^{3}$
}

\begin{abstract}
This research work aims to investigate the mechanically alloyed $\mathrm{Fe}_{15} \mathrm{Co}_{2} \mathrm{P}_{3}$. Parametric Rietveld refinement method, of the obtained X-ray patterns, was performed for qualitative and quantitative phase analysis, structural, microstructural and mechanical properties. The ball-milled powder mixture crystallized within the face-centred cubic $\alpha-F e(\mathrm{P})$ solid solution in equilibrium with $\mathrm{Co}_{75} \mathrm{Fe}_{25}$ phase. The crystallite size decreases reaching 100 and $200 \mathrm{~nm}$ respectively after $3 \mathrm{~h}$ of milling. The highest values of the dislocation density, microstain and stored energy are registered for the $\alpha-F e(\mathrm{P})$ solid solution. The studied mechanical properties manifest the brittle nature of the $\alpha-F e(\mathrm{P})$ solid solution compared to the $C_{75} F_{2} e_{25}$ phase. The squareness ratio $M_{\mathrm{r}} / M_{\mathrm{s}}$ and the coercivity values of the milled powders increase with increasing milling time and reach steady state after $2 \mathrm{~h}$. The hysteresis loss energy and maximum permeability reach minimal values of $45^{*} 10^{-4} \mathrm{~W} / \mathrm{m}^{3}$ and $49 * 10^{-3} \mathrm{H} / \mathrm{m}$ respectively, after $1 \mathrm{~h}$ of milling at the opposite of the switching field distribution.
\end{abstract}

Keywords $\mathrm{Fe}_{15} \mathrm{Co}_{2} \mathrm{P}_{3}$; Ball milling, XRD; Rietveld; Mechanical; Magnetic.

\section{Introduction}

The magnetic nanoparticles $\mathrm{Fe}$ - $\mathrm{Co}$ based alloys have been the subject of many researches due to their potential applications such as medical hyperthermia and targeted drug delivery [1]. When entered cancer cells, an external

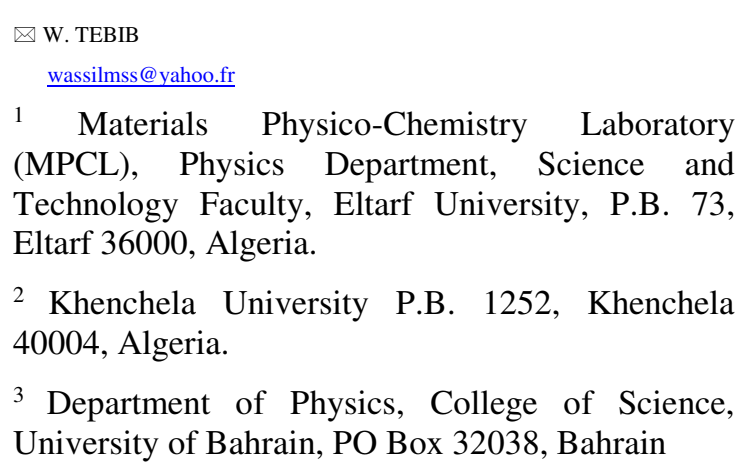
Technology Faculty, Eltarf University, P.B. 73, Eltarf 36000, Algeria.

2 Khenchela University P.B. 1252, Khenchela 40004, Algeria.

3 Department of Physics, College of Science, University of Bahrain, PO Box 32038, Bahrain

source applied to activate these magnetic nanoparticles lead to the destruction of pathological cells by physic-chemical effect [2]. Moreover, iron oxides and derivative nanoparticles act as an agent for the advancement of clinical regenerative medicine and magnetoresponsive therapy using magnetic resonance imaging tracking or multimodal imaging [3, 4]. Other studies reveal that calcium phosphate $\mathrm{CaP}$ and indium phosphides $\operatorname{InP}$ based alloys have an influence on biocompatibility property $[5,6]$. The magnetic hyperthermia is a type of thermal treatment of cancer; the ferromagnetic nanoparticles once localized in cancer cells, under external magnetic field will heat up resulting in the death (burn out) of 
cancer cells. Thus, heat can be used as a support of the therapeutic effects of other treatments by reducing the covering of cancer cells from anti-cancer activities $[7,8]$. Hence, magnetic $\mathrm{Fe}-\mathrm{Co}-\mathrm{P}$ alloys due to their interesting properties, are considered as promising candidates for wide range of applications, including from media storage as the $\mathrm{Fe}-\mathrm{Co}-\mathrm{P} / \mathrm{C}$ [9] to magnetic memory devices to vector probes in the biomedical research and clinical diagnostics and therapeutics $[10,11]$.

Most of $\mathrm{Fe}$ - $\mathrm{Co}-\mathrm{P}$ alloys were produced as amorphous and/or crystalline nanowires by electrochemical deposition process [12] whereas in the biomedical field powder is recommended for the preparation of suspensions that can subsequently be easily administered to the human body. For this purpose, in this study $\mathrm{Fe}$ - $\mathrm{Co}-\mathrm{P}$ alloys will be prepared in the form of powder by mechanical milling technique, which was used frequently to mix powders to achieve a homogeneous alloy through successive welding, fracturing and rewelding processes [13].

Similarly, binary systems such as $\mathrm{Fe}-\mathrm{P}$ and $\mathrm{Fe}$ - $\mathrm{Co}$ based alloys were also prepared by mechanical alloying and exhibited interesting properties [14, 15]. In one hand, $\mathrm{Fe}$-Co alloys attracted great attention due to their excellent soft magnetic and mechanical properties, which are found to be strongly dependent on the adopted fabrication method and subsequent heating treatment $[16,17]$. They are widely known by their high specific saturation magnetization, low coercivity, high permeability, and high Curie temperature, making them promising for high temperature applications besides being competitive candidates with other highly magnetic materials $[18,19]$. In the other hand, the transition metal phosphides alloys and their solid solutions demonstrated interesting magnetic properties which are greatly influenced by both the type of the crystal structure and the chemical composition; for instance it was reported that the lattice parameters and Curie temperature of $F_{2-x} P$ system changes significantly with the presence of small amount of impurities and the deviation of stoichiometry [20]. The role of the compound on the structure stability, phase composition and properties was mostly studied on binary $\mathrm{Fe}$ - $\mathrm{P}$ alloys that dependent on $\mathrm{P}$ concentration with a ferromagnetic ground state [14, 21]. In recent years, great attention has been given to the thermal stability of transition metal phosphides nanomaterials [22, 23]. Others studies of $\mathrm{Co}_{2} \mathrm{P}$ encapsulated in $\mathrm{N}, \mathrm{P}-$ doped grapheme, CoMnP nanoparticles, nanostructured $\mathrm{Fe}_{92} \mathrm{P}_{8}$ and $\mathrm{Fe}-\mathrm{Co}$, $\mathrm{MnFeP} \mathrm{I}_{-y} \mathrm{As} s_{y},\left(\mathrm{Fe}_{\mathrm{I}_{-x} \mathrm{Mn}} \mathrm{n}_{3}\right)_{3} \mathrm{P}, \mathrm{Li}-\mathrm{Fe}-\mathrm{P}$ and $\mathrm{FeP}$ alloys report a robust catalytic activity [24, 25], interesting magnetic [26, 27], electronic and mechanical properties [28, 29], and a good storage energy capacity [30, 31]. These properties can be altered by changing the chemical composition, type of crystal structure, and grain size. These nanostructured materials formed by mixing a metal with phosphorus are wellknown by their metalloid characteristics with good electrical conductivity [32], which is important for electrochemical applications.

Moreover, numerous studies report on the fabrication of $\mathrm{Fe}$ - $\mathrm{Co}-\mathrm{P}$ alloys by different techniques such as reacting low-reactive metal-oleates $\left(\mathrm{Co}^{2+}\right.$ and $\left.\mathrm{Fe}^{3+}\right)$ with trioctylphosphine [33], electrodeposition [34, 12], drop synthesis method [36], organic phase reaction $[37,38]$, phase- 
solution method [39], and electroless plating method [40]. Herein, it is important to highlight that phosphorus was added to $\mathrm{FeCo}$ alloy to improve the soft magnetic performance of the mixture the magnetic permeability as well as provides strengthening to the solid solution within the matrix [41, 42].

The present work aims to study the elemental $(\mathrm{Fe}, \mathrm{Co}$ and $\mathrm{P})$ powder mixture through atomic diffusion during the mechanical alloying process. Particular emphasis will be devoted to the evolution of structural and microstructural as function of milling time, and subsequently the correlation with the mechanical and magnetic properties. This study primarily focuses on the fabrication of nanostructured powder by optimizing their manufacturing protocol and analysis for a future preformulation of active nanosuspensions.

\section{Materials and methods}

Pure elemental powders of iron, $\mathrm{Fe}$ (97\%, average particle size $\sim 325$ mesh), cobalt, Co $(99.90 \%$ average particle size $\sim 150$ $\mu \mathrm{m})$, and amorphous red phosphorus, $P$ (99.9\%), were mixed in a high energy planetary ball mill Retsch PM 400. The milling process was performed at room temperature under an inert atmosphere using hardened steel balls and vials. The milling speed was fixed at $350 \mathrm{rpm}$ with a ball-to-powder weight ratio of 10:3 while the milling time vas varied from 1 to $3 \mathrm{~h}$ with a pause of $30 \mathrm{~min} / \mathrm{h}$.

The structure of the milled powder was checked by X-ray diffraction (XRD) using a Bruker-D8 advanced diffractometer in a $(\theta-2 \theta) \quad$ Bragg-Brentano geometry equipped with $C u-K \alpha$ radiation source $\left(\lambda_{C u}\right.$ $=0.15406 \mathrm{~nm}$ ). Qualitative and quantitative phase analysis of XRD patterns was investigated by the Rietveld method [43] using the MAUD program version 2.26 [44]. The magnetic measurements were carried out at $300 \mathrm{~K}$ using the vibrating sample magnetometer (VSM) MicroSence-EZ7 under an applied magnetic field of $20 \mathrm{kOe}$.

The phase composition, structural, microstructural and mechanical parameters were determined by the refinements of XRD patterns by means of MAUD program [43]. The effective crystallite size and roots mean square (r.m.s) of microstrain were obtained by fitting the peaks profile using the pseudo-voigt function, which is a combination of a Gaussian and a Lorentzian peaks shape [45]. The refinement program minimized, by an algorithm based on the least squares method, the function $M$ called residue where its absolute value is defined by [46]:

$M=\sum_{i} w_{i}\left(y_{i}-y_{c i}\right)^{2}$

where $y_{i}$ and $y_{c i}$ are, respectively, the observed and calculated intensity; $w_{i}=1 / y_{i}$ is the weight associated to the $i^{\text {th }}$ observed count.

The calculated intensity is obtained by summing different contributions of Bragg diffraction peaks and the background [47]:

$y_{c i}=y_{b i}+\sum_{\phi=1}^{p h a s e} s_{\phi}, \sum_{K=1}^{p i c s} j_{\phi K}, L P_{\phi K}, O_{\phi K}, A_{1}\left|F_{\phi K}\right|^{2}, \Omega_{i \phi K}$

with $K$ the Miller's indices for a reflection $(h, k, l) ; y_{b i}$ the continuous background intensity; $S_{\phi}$ the scale factor, proportional to the volume fraction of each refined phase; $j_{\phi k}$ the multiplicity factor of the $\mathrm{k}^{\text {th }}$ reflection peak; $L_{P \phi k}$ the LorentzPolarization factor; $O_{\phi k}$ the correction factor describing the preferred orientation; 
$A$ the absorption factor; $\mathrm{F}_{\phi \mathrm{K}}$ the structure factor; and $\Omega_{i \phi k}$ the profile shape function.

The quality of the refinement with the MAUD program is characterized by the reliability weighted, $R_{w}$, and expected factor, $R_{\text {exp }}$, or just by the goodness of fit, $\chi$, defined as follow:

$$
\begin{aligned}
& R_{w p}=\sqrt{\frac{\sum_{i} w_{i}\left(y_{i}-y_{c i}\right)^{2}}{\sum_{i}\left(w_{i} y_{i}\right)^{2}}} \\
& R_{\exp }=\left(\frac{N-p}{\sum_{i}\left(w_{i} y_{i}\right)^{2}}\right)^{1 / 2} \\
& \chi^{2}=\frac{R_{w p}}{R_{\exp }}
\end{aligned}
$$

where $N$ and $P$ are the number of experimental points and refined parameters, respectively.

The dislocation density, $\rho$, is one of the important parameter influencing the final microstructure, is calculated by [48]:

$$
\rho=2 \sqrt{3} \frac{\left.<\sigma^{2}\right\rangle}{\langle L\rangle B}
$$

where $B$ is the Burger's vector, which is equal to $a(\sqrt{ } 2 / 3)$ for the $<110>$ direction of the $b c c$ structure, $\langle L\rangle$ the crystallite size and $\left\langle\sigma^{2}\right\rangle^{1 / 2}$ the root mean square (r.m.s) microstrain, obtained by the Rietveld refinements.

The planar defects expressed in terms of stacking faults probabilities, SFP, are given by $[49,50]$ :

$S F P=\left[1.5\left(\alpha^{\prime}+\alpha^{\prime}\right)+\beta\right]$

Where $\alpha^{\prime}, \alpha$ ' are the intrinsic and extrinsic deformation faults probabilities, respectively, and $\beta$ is the twin faults one.

To calculate the stored energy, $E_{S}$, the following formula is used [51]:

$E_{S}=\left[3 E / 2\left(1+2 v^{2}\right)\right]\left\langle\sigma^{2}\right\rangle$

Where $E$ is Young's modulus and $v$ is Poisson ratio.

\section{Results and discussion}

\subsection{Structural and microstructural properties}

The best Rietveld refinements of XRD patterns of the powder mixture $\mathrm{Fe}_{15} \mathrm{Co}_{2} \mathrm{P}_{3}$ as function of milling time have been obtained using an isotropic fitting model with the combination of different phases. For the un-milled powder mixture, the starting structural model is based on the elementary powders of $s c-P, b c c-\alpha-F e$ and Co-hexagonal. However, for the XRD pattern of the milled powder mixture, the best Rietveld refinements has been found with two $b c c$ phases only; an $\alpha-F e(P)$ solid solution and a binary $\mathrm{Co}_{75} \mathrm{Fe}_{25}$ phase with $\mathrm{Im}-3 \mathrm{~m}$ space group. Figure 1 displays the $X R D$ refined patterns of the un-milled and ball-milled $\mathrm{Fe}_{15} \mathrm{Co}_{2} \mathrm{P}_{3}$ powder mixture using the MAUD program [44], manifesting the evolution of the alloying as a function of milling time. From Figure 1 , one can observe that the variation of peaks relative intensity with milling time indicates the corresponding change of phase's composition, whereas peaks' broadening indicates the occurrence of grain refinement and accumulation of microstrain induced by severe plastic deformations during the milling process.

The initial mixture displays the diffraction peaks characteristics of pure $b c c \alpha-F e$ and Co-hcp in addition to $P$, whereas the latter disappears after milling evidenced by the dissolution of $P$ into the $\alpha-F e$ host lattice by solid state reaction accompanied by the formation of the $\alpha-F e(P)$ solid solution. Similarly, Co atoms will diffuse and incorporate into $\alpha-F e$ host lattice leading to the formation of $\mathrm{CO}_{75} \mathrm{Fe}_{25}$ phase after 1 $\mathrm{h}$ of milling. The formation of this phase is due to its higher thermodynamic stability under the experimental milling conditions 
compared to other phases present in the binary $\mathrm{Fe}$-Co phase diagram. In fact, it is important to highlight that this phase has been obtained under an ultrahigh-vacuum chamber at a low pressure by molecular beam epitaxy (MBE) [52] and synthesized by $D C$ magnetron sputtering deposition on top of a tunneling barrier of $\mathrm{AlO}_{\mathrm{x}}$ [53]. Accordingly, the presence of $P$ atoms in the studied mixture facilitates the precipitation of $\mathrm{Co}_{75} \mathrm{Fe}_{25}$ into an $\alpha-\mathrm{Fe}(\mathrm{P})$ solid solution with lesser energy. This is probably due to the small difference between the atomic radii of the host metal, $F e$, and the dissolved $P\left(r_{F e}=0.125 \mathrm{~nm}, r_{P}\right.$ $=0.128 \mathrm{~nm})$, hence preferring $\mathrm{a}$ substitutional site within the $F e$ crystal lattice [54]. The $\alpha-F e(P)$ solid solution was also obtained at much higher milling time of 9,12 and $21 \mathrm{~h}$ [55] with subsequent annealing at $210^{\circ} \mathrm{C}$ under argon for $30 \mathrm{~min}$ [56].

The relative deviation of the unit cell volume from that of the perfect crystal $\mathrm{V}_{0}$ as defined by $\Delta V / V_{0}=\left(V-V_{0}\right) / V_{0}$, is found to be nearly constant after $1 \mathrm{~h}$ of milling (Fig. 2a). The deviation increases after the first hour of milling is due to the deformation of the crystal structure of both $\alpha-\mathrm{Fe}(\mathrm{P})$ and $\mathrm{CO}_{75} \mathrm{Fe}_{25}$ phases, associated with the repeated fracturing, cold welding and re-welding processes of the newly formed powdered particles and the diffusion of both $P$ and $C o$ atoms within the host lattice of $\mathrm{Fe}$. The obtained results reveal that the unit cell volume expansion of the newly formed $\mathrm{Co}_{75} \mathrm{Fe}_{25}$ phase is higher than that of the $\alpha-F e(P)$ solid solution. In fact, after $3 \mathrm{~h}$ of milling, $\Delta V / V_{0}$ of $\mathrm{Co}_{75} \mathrm{Fe}_{25}$ is in the order of $5.26 \pm 0.02 \%$, which is two times higher than $2.5 \pm 0.02 \%$ for $\alpha-F e(P)$, signifying that the structure of the $\mathrm{Co}_{75} \mathrm{Fe}_{25}$ phase is more deformed than that of the $\alpha-F e(P)$ solid solution. These results can be correlated with the values of the internal microstrain $\left\langle\sigma^{2}\right\rangle^{1 / 2}$ deduced from the Rietveld refinements of the XRD patterns; i.e. $0.4 \times 10^{-3} \pm 0.0002$ for $\mathrm{Co}_{75} \mathrm{Fe}_{25}$ compared to $0.2 \times 10^{-3} \pm 0.0002$ for $\alpha-F e(P)$ solid solution, after $3 \mathrm{~h}$ of milling.

Figure $2 b$ illustrates the variation of phase composition as a function of milling time. The percentage of the formed $\mathrm{Co}_{75} \mathrm{Fe}_{25}$ phase increases rapidly, in the first milling hour, at the expense of pure $\mathrm{Co}$ and $\mathrm{Fe}$ elements reaching $\sim 60 \%$. In fact, pure $\alpha$ $\mathrm{Fe}$ has the highest percentage before milling of $\sim 75 \%$ then varies with milling time to reach $35 \%$ after $3 \mathrm{~h}$ milling.

To better understand the pure element diffusion within the host lattice and subsequently the formation mechanism occurring by the mechanical milling process, primarily well-defined planar crystallographic defects playing a key role in solid state reactions has been chosen carefully. Thus, Figure 2c illustrates the evolution of the antiphases' presence probability during the milling in both $\alpha$ $\mathrm{Fe}(\mathrm{P})$ solid solution and $\mathrm{Co}_{75} \mathrm{Fe}_{25}$ structures deduced from the XRD Rietveld refinements. The highest probability values are recorded for the newly formed $\mathrm{Co}_{75} \mathrm{Fe}_{25}$ phase, which corroborate with the variation of its unit cell volume. Alternatively, the stacking fault probability, $S F P$, is found to be very weak in the binary $\mathrm{C}_{075} \mathrm{Fe}_{25}$ phase but increases with milling time for the solid solution (Fig. 2d). The increase of SFP, intimately related to the creation and reaction of dislocations, with extensive milling time reflects an important increase in the dislocations density in $\mathrm{Fe}$ crystal lattice (Fig. 2e). These results highlight the 
pathway of the solid state reactions in this compound, occurring by diffusion of both elemental $P$ and $C o$ within $F e$ host lattice through stacking faults as well as dislocations induced by the milling process into the solid solution and $\mathrm{Co}_{75} \mathrm{Fe}_{25}$ phase. As a host, the bcc $\alpha$-Fe phase can dissolve $P$ atoms thereby creating lattice defects such as dislocations and grain boundaries. The increase of the SFP after $2 \mathrm{~h}$ of milling can be attributed to the annihilation of dislocations to minimize their energy. It is clear that the dislocations density of $\mathrm{Co}_{75} \mathrm{Fe}_{25}$ phase is steady and reaches the smallest value of about $2.22 \times 10^{10} \mathrm{~m}^{-2}$.

The accumulation of lattice defects induced during milling, manifested by the variation of the microtrain rate $\left\langle\sigma^{2}\right\rangle^{1 / 2}$, has a direct influence on the evolution of the crystallite size $\langle L\rangle$ of the obtained phases in the milled $\mathrm{Fe}_{15} \mathrm{Co}_{2} \mathrm{P}_{3}$ powder mixture (Fig. 2f-g). Accordingly, for $\alpha-F e(P)$ solid solution, the crystallite size decreases drastically from $483 \mathrm{~nm}$ to reach an average value of about $100 \mathrm{~nm}$ from 1 to 3 $\mathrm{h}$ of milling. Meanwhile, the crystallite size of $\mathrm{Co}_{75} \mathrm{Fe}_{25}$ phase is found to be nearly stable with milling time and reaches a mean value of $193 \mathrm{~nm}$.

\subsection{Mechanical properties}

The evolution of the simulated mechanical properties such as Young modulus and Poisson ratio, have been deduced from the $X R D$ Rietveld refinements. The highest value of Young modulus, $E$, in the milled $\mathrm{Fe}_{15} \mathrm{Co}_{2} \mathrm{P}_{3}$ powder mixture is $\sim 200 \mathrm{GPa}$, which is close to that of coarsed metals but higher than that of other nanomaterials such as $\mathrm{FeCoP}$ nanoglass films i.e. 138.85 $\mathrm{GPa}$ [57]. However, this estimated value is slightly smaller compared to that of $\mathrm{Fe}_{60} \mathrm{Co} 40$ alloy of $250 \mathrm{GPa}$ [58] but almost three times lower than the monolithic
FeCo alloy setting in the range 611 - 536 $\mathrm{MPa}$ [59]. The results obtained in this study reflect the influence of the addition of $P$ powder to the $\mathrm{Fe}$ - $\mathrm{Co}$ system, as consequence a dramatic decrease in the Young modulus values compared to $\mathrm{Fe}$ - $\mathrm{Co}$ binary alloys. This can be attributed to the precipitation of the $\mathrm{Co}_{75} \mathrm{Fe}_{25}$ particles embedded in the $\alpha-F e(P)$ solid solution during the milling process, resulting in the weakness and rigidness of final powder mixture because the initial powder mixture is ductile $(\mathrm{Co}, \mathrm{Fe})$ - brittle $(\mathrm{P})$ type. The Poisson ratio (Fig. 3a) of the $\mathrm{Co}_{75} \mathrm{Fe}_{25}$ phase reaches a nearly stable mean value during the milling while for the $\alpha-F e(P)$ solid solution it has lower values and decreases gradually with milling time. The above results expose the brittle nature of the $\alpha-F e(P)$ solid solution in comparison with the $\mathrm{Co}_{75} \mathrm{Fe}_{25}$ phase. Moreover, the evolution of the calculated stored energy as a function of milling time (Fig. 3b) shows that the prevalent value of the stored energy is observed for the $\alpha-F e(P)$ solid solution after $1 \mathrm{~h}$ of milling. The values of the stored energy in the $\mathrm{Co}_{75} \mathrm{Fe}_{25}$ phase are very weak and nearly equal to $83 \times 10^{-6} \mathrm{~J} / \mathrm{mol}$. These results may be attributed to the high rate of microstain and dislocations density in the nanometric $\alpha-\mathrm{Fe}(\mathrm{P})$ grains compared to those of $\mathrm{Co}_{75} \mathrm{Fe}_{25}$ phase.

\subsection{Magnetic Properties}

The magnetization-field hysteresis $(\mathrm{M}-\mathrm{H})$ curves of the $\mathrm{Fe}_{15} \mathrm{Co}_{2} \mathrm{P}_{3}$ powder mixture recorded at room temperature are displayed in Figure 4a, with the inset representing $\mathrm{M}-\mathrm{H}$ curves at low fields. All M-H curves exhibit similar soft magnetic features of the powder mixture with an extremely thin hysteresis loops, irrespective of the milling time. This shape 
is determined by the domain state which can be distinguished by several parameters such as the coercive field, $H_{c}$, the squareness ratio $M_{r} / M_{s}$, the switching field distribution, $S F D$, magnetic permeability, $\mu_{\text {max }}$ and loss energy $Q_{h}$.

The maximum energy loss of the hysteresis loop in the $2^{\text {nd }}$ and $4^{\text {th }}$ quadrant of the hysteresis loop is presented in Figure 4b. A very small hysteresis loss is implied by the resulting narrow of the hysteresis loop. This type of loss strongly depends on the crystallite size, residual stresses and density of the material. According to the obtained results, for the $\mathrm{Fe}_{15} \mathrm{Co}_{2} \mathrm{P}_{3}$ compound, the hysteresis loss shows a higher value of $6.94 \times 10^{-3} \mathrm{~W} / \mathrm{m}^{3}$ in un-milled powder mixture due to the large crystallite size. The hysteresis loss decreases for the first hour of milling following an important reduction of the crystallite size [60], then increases with further milling to reach a steady state between 2 and $3 \mathrm{~h}$.

Indeed, the evolution of the coercive field $H_{c} \quad v s$. the average grain size of the $\mathrm{Fe}_{15} \mathrm{Co}_{2} \mathrm{P}_{3}$ powder mixture as a function of milling time (Fig. 4c), manifests a gradual increase up to $2 \mathrm{~h}$ of milling while the average grain size decreases then reaches a steady state. The increase of the coercive field is related to the growth of the microstrain ratio introduced during milling and can be explained through the theory of soft magnetic materials [61]. Additionally, one can observe the evolution of the nucleation field $H_{n}$ of the $\mathrm{Fe}_{15} \mathrm{Co}_{2} \mathrm{P}_{3}$ powder mixture $H_{n}$, which means that a magnetization state becomes unstable and the change in the magnetization configuration begins. However, the nucleation field is nearly close to the coercive field $H_{c}\left(H_{n} \approx H_{c}\right.$, indicating that the milled powder mixture is nearly a perfect magnet.

The squareness ratio $M_{r} / M_{s}$ (Fig. 4d) increases gradually with the milling time then reaches stability up to $2 \mathrm{~h}$. The rise of the $\mathrm{M}_{\mathrm{r}} / \mathrm{M}_{\mathrm{s}}$ ratio can be associated with the crystallization process that leads to the increase in the magnetic anisotropy. From the values of the squareness ratio $M_{r} / M_{s}$, it is possible to differentiate between single domain and multi-domain particles. Thus, the obtained values of $M_{r} / M_{s}$ ratio in the range of 0.07 to 0.09 are much lower than the expected values [62], which reached 0.95 for the ferromagnetic $\mathrm{Co}_{75} \mathrm{Fe}_{25}$ alloy [63].

The switching field distribution, $S F D$, is an important micromagnetic characteristic curve depending on the degree of alignment of particles along the easy axis. It is supposed that the extracted $S F D$ from macroscopic measurements rely on separating the contributions to the measurements of the intrinsic SFD, the extrinsic effects of magnetostatic and exchange interactions. The characteristic features of interphase exchange coupling are illustrated by switching field distribution via $d H / d H_{c} v s$. the milling time (Fig. 4e), where $d H$ is the field between $0.5 M_{r}$ and - $0.5 M_{r}$ whereas $H_{c}$ is the coercivity. The distribution of the switching field shows one peak at $1 \mathrm{~h}$ of milling a typical characteristic of soft phases, indicating the magnetization reversal is completed in one-step for this powder mixture. Consequently, the width of the $d H / d H_{c}$ peak can be interpreted as an estimation of the efficiency of hard/soft interphase exchange coupling.

Figure $4 \mathrm{f}$ shows the maximum magnetic permeability $\mu_{\max }$ of the $\mathrm{Fe}_{15} \mathrm{Co}_{2} \mathrm{P}_{3}$ powder mixture as a function of milling time. It can be seen that the maximum 
permeability decreases after $1 \mathrm{~h}$ of milling compared with its value before milling then increases with milling time to reach a maximum permeability value of about $65 \times 10^{-3} \mathrm{H} / \mathrm{m}$ after $3 \mathrm{~h}$ of milling. This can be attributed to the presence of a nonmagnetic $P$ element within the $\alpha-F e(P)$ solid solution in the powder mixtures which acts like an air gap, as a source of demagnetizing field causing the existence of very mobile domain walls. As consequence, the maximum permeability value increases, since it is reported that the permeability is sensitive to the microstructure and thereby can be affected by the shape of the particles, density, porosity and strongly depends on the grain size $[64,65]$. It is well-known that addition of $P$ increases the permeability while decreases the coercivity $[66,67]$. This, as suggested by the above magnetic results is due to the higher phosphorus concentration $\sim 15$ (wt.\%) in the $\alpha-F e(P)$ solid solution.

The observed variation in the magnetic properties of the milled $\mathrm{Fe}_{15} \mathrm{Co}_{2} \mathrm{P}_{3}$ powder mixture may also be correlated indirectly with the fabrication parameters, for instance milling atmosphere, milling speed, rise of the local temperature, and so on. Indeed, it's well established that the effect of temperature on ferromagnetism is very important. When the temperature increases, the thermal energy tends more and more to break the spontaneous alignment of atoms. The increase of the local temperature during the milling process can modify the magnetic properties of materials mainly by an irreversible change in their local chemical composition and homogeneity.

\section{Conclusion}

$A$ soft magnetic $\mathrm{Fe}_{15} \mathrm{Co}_{2} \mathrm{P}_{3}$ alloy was successfully prepared by mechanical alloying from elemental $\mathrm{Fe}, \mathrm{Co}$ and red $P$ powders. The Rietveld refinements of the $X R D$ patterns revealed that, irrespective of the milling time, only bcc-type structures are formed and present Lorentizien Bragg diffraction peaks, with grain refinement and accumulated microstrain. $60 \%$ of the formed compound is a $\mathrm{Co}_{75} \mathrm{Fe}_{25}$ phase after $1 \mathrm{~h}$ of milling with the highest antiphases boundaries and deformed grains. The crystallite size decreased to 100 - 200 $\mathrm{nm}$ after $3 \mathrm{~h}$ of milling. The high values of the SFP reflected an important increase in the dislocations density in $\mathrm{Fe}$ host lattice and manifested the solid state reaction pathway which takes place through dislocations and stacking faults. The value of Young modulus in the $\mathrm{Fe}_{15} \mathrm{Co}_{2} \mathrm{P}_{3}$ powder mixture was found smaller than that obtained in binary $\mathrm{Fe}-\mathrm{Co}$ alloys, reflecting the effect of $\mathrm{P}$ addition. A narrow hysteresis loop suggested a very low hysteresis loss. The coercivity was found to increase with milling time while the average grain size decreases; which is accompanied by an enhancement of the microstrain ratio. Different magnetic properties such as hysteresis loss energy, magnetic susceptibly and switching field distribution are determined, which help in defining the manufacturing protocol with a better preformulation of active magnetic nanosuspensions for biomedical applications.

\section{Acknowledgments}

This work was supported by the Algerian Directorate for Scientific Research and Technological Development (DGRSDT). The authors warmly thank Dr. Ali Hafs for VSM characterization. 


\section{Declarations}

a. Funding (information that explains whether and by whom the research was supported)

No funding was received for conducting this study.

b. Conflicts of interest/Competing interests (include appropriate disclosures)

The authors have no conflicts of interest to declare that are relevant to the content of this article.

c. Availability of data and material (data transparency)

Non applicable.

d. Code availability (software application or custom code)

Non applicable.

e. Ethics approval (include appropriate approvals or waivers)

Non applicable.

f. Consent to participate (include appropriate statements)

All authors agreed with the consent to participate.

g. Consent for publication (include appropriate statements)

All authors read and gave their consent for the publication of this article.

h. Authors' contributions (optional: please review the submission guidelines from the journal whether statements are mandatory)

Hanane BERKANI (PhD Student): validation, investigation, resources, writing original draft, writing - review \& editing, visualization.

Prof. Rachid SIAB (Supervisor): conception, methodology, resources, supervision.

Prof. Wassila TEBIB (Co-Supervisor): conception, methodology, resources, review \& editing, visualization, supervision, validation.

Dr. Locif REDOUANI (XRD Manager): XRD measurements and data base, visualization.

Saida BOUKEFFA (PhD Student): XRD refinement, visualization.

Prof. Mohamed Bououdina (Research Collaborator): validation, writing - review \& editing, visualization, 


\section{References}

1. Najafi A, Nematipour K (2007) Synthesis and magnetic properties evaluation of monosized FeCo alloy nanoparticules through microemulsion method. J Supercond Nov Magn. 30(9):2647-2653.

https://doi.org/10.1007/s10948-017-40522.

2. Marcel L, Patrick B, Philippe H (2007) Les Nanosciences. Tome 3. Nanotechnologie et Nanobiologie, Belin.

3. Mahmoudi M, Hosseinkhani $\mathrm{H}$, Hosseinkhani M, Boutry S, Simchi A, Journeay WSh, Subramani K, Laurent S (2011) Magnetic resonance imaging tracking of stem cells in vivo using iron oxide nanoparticles as a tool for the advancement of clinical regenerative medicine. Chem. Rev. 111: 253-280. https://doi.org/10.1021/cr1001832

4. Lee N, Cheon J, Yoo D, Ling D, Cho MH, Hyeon $\mathrm{T}$ (2015) Iron oxide based nanoparticles for multimodal imaging and magnetoresponsive therapy. Chem. Rev. 115:10637-10689.

https://doi.10.1021/acs.chemrev.5b00112.

5. Shekhar N, Rajesh T, Bikramjit B (2009) Understanding phase stability, microstructure development and biocompatibility in calcium phosphatetitania composites, synthesized from hydroxyapatite and titanium powder mix. Mater. Sci. Eng., C. 29:97-107. https://doi.10.1016/j.msec.2008.05.019.

6. Giulia V, Maria M, Hiram CM, Lucia M, Giada O, Karl DW, Wai LL, Peter R, $\begin{array}{llll}\text { Claudia } & T & \text { (2019) In vivo }\end{array}$ biotransformations of indium phosphide quantum dots revealed by X-ray microspectroscopy. ACS Appl. Mater.
Interfaces.

11:35630-35640.

https://doi.10.1021/acsami.9b15433.

7. Hergt R, Dutz S, Müller R, Zeisberger M (2006) Magnetic particle hyperthermia: nanoparticle magnetism and materials development for cancer therapy. J. Pys.: Condens. Matter. 18:S2919-S2934. https://doi.10.1088/0953-8984/18/38/S26

8. Noh SH, Moona SH, Shin TH, Lim Y, Cheon J (2017) Recent Advances of Magneto-Thermal Capabilities of Nanoparticles: From Design Principles to Biomedical Applications. Nano Today. 13:61-76.

https://doi.org/10.1016/j.nantod.2017.02.0 06

9. Li X, Qian X, Xu Y, Wu H, Dan Y, Chen L, Yu Q (2019) Fe-Co-P/C with strong coupling interaction for enhanced sodium ion batteries and oxygen evolution reactions. Electrochim.Acta. 321:134646. https://doi.org/10.1016/j.electacta.2019.13 4646.

10. Cheon J, Lee JH (2008) Synergistically integrated nanoparticles as multimodal probes for nanobiotechnology. Acc. Chem. Res.

41(12):1630-1640. https://doi.10.1021/ar800045c.

11. Cheon J, Jun YW, Seo JW, Jinwoo Ch (2008) Nanoscaling laws of magnetic nanoparticles and their applicabilities in biomedical sciences. Acc. Chem. Res. 41:179-189. https://doi.10.1021/ar700121f 12. Xue DS, Fu JL, Yan ZJ, Xu Y, Fan LX (2007) Effects of annealing temperature on structure and magnetic properties of amorphous $\mathrm{Fe}_{61} \mathrm{Co}_{27} \mathrm{P}_{12}$ nanowire arrays. J. Phys. Chem. Solids. 68:2221- $2226 . \quad$ https://doi. org/10.1016/j.jpcs.2007.06.023.

13. Grigorieva TF, Barinova AP, Lyakhov N Z (2008) Mechanochemical synthesis in 
mechanochemical systems [in Russian]. Parallel, Novosibirsk. 1-311

14. Tebib W, Alleg S, Bensalem R, Grenèche JM (2010) Structural Study of the Mechanically Alloyed Fe-P. Int. J. Nanoparticles.

3:237-245. https://doi.org/10.1504/IJNP.2010.035879 15. Chakka VM, Altuncevahir B, Jin ZQ, Li Y, Liua JP (2006) Magnetic nanoparticles produced by surfactantassisted ball milling. J. Appl. Phys. 99:08E912.

https://doi.org/10.1063/1.2170593

16. Manh DH, Tung DKh, Nam DNH, Hong LV, Phong PhTh, Phuc NX (2014) Magnetic properties of annealed $\mathrm{Fe}_{65} \mathrm{Co}_{35}$ powders prepared by mechanical alloying. IEEE T MAGN. 50:1-4. https://doi.10.1109/TMAG.2014.2303078

17. Zeng Q, Baker I, McCrearyb V, Yanc $\mathrm{Zh}$ (2007) Soft ferromagnetism in nanostructured mechanical alloying $\mathrm{FeCo}-$ based powders. J. Magn. Magn.Mater. 318:28-38.https://doi. org/10.1016/j.jmmm.2007.04.037.

20. Tebib W, Alleg S, Bensalem R, Bensebaa N, Bentayeb FZ, Suñol JJ, Grenèche JM (2008) Structural characterization of nanostructured $\mathrm{Fe}-8 \mathrm{P}$ powder mixture. J. Nanosci. Nanotechnol. 8:

2029-2036.

https://doi.10.1166/jnn.2008.056.

18. Sundaram K, Dhanasekaran V, Mahalingam T (2011) Structural and magnetic properties of high magnetic moment electroplated CoNiFe thin films. Ionics.

$17: 835-842$. https://doi.10.1007/s11581-011-0580-0.

19. Pfeifer F, Radeloff C (1980) Soft magnetic $\mathrm{Ni}-\mathrm{Fe}$ and $\mathrm{Co}-\mathrm{Fe}$ alloys-some physical and metallurgical aspects. J. Magn. Magn. Mater. 19:190-207. https://doi.org/10.1016/0304-

8853(80)90592-2.
21. Liu XB, Ping LJ, Zhang Q, Altounian Z (2013) Fe magnetic moment formation and exchange interaction in $\mathrm{Fe}_{2} \mathrm{P}$ : A firstprinciples study. Phys. Lett. A. 377:731735.

https://doi.org/10.1016/j.physleta.2013.01. 019.

22. Tebib W, Alleg S, Grenèche JM, Suñol JJ (2018) Thermal stability of the nanocrystalline Fe-8P (wt. \%) powder produced by ball milling. Phosphorus, SulfurSilicon Relat. Elem. 193:500-506. https://doi.org/10.1080/10426507.2018.14 52233.

23. Tebib W, Chenouga I (2018) Effects of substitutional site in mechanical behavior of highly reactive nanostructured iron phosphides alloys. J. Physics and Energetics. 2:26-30.

24. Zhuang M, Ou X, Dou Y, Zhang L, Zhang Q, Wu R, Ding Y, Shao M, Luo Zh (2016) Polymer-embedded fabrication of $\mathrm{Co}_{2} \mathrm{P}$ nanoparticles encapsulated in N,Pdoped graphene for hydrogen generation. Nano Lett. 16: 4691-4698. https://doi. org/10.1021/acs.nanolett.6b02203

25. Li D, Baydoun H, Verani CN, Brock SL (2016) Efficient water oxidation using CoMnP nanoparticles. J. Am. Chem. Soc. 138:4006-4009.

https://doi.org/10.1021/jacs.6b01543

26. Bensalem R, Tebib W, Allag S, Suñol JJ, Bessais L, Greneche JM (2009) Magnetic properties of nanostructured $\mathrm{Fe}_{92} \mathrm{P}_{8}$ powder mixture. J. Alloy Compd. 471:24-27. https://doi.10.1016/j.jallcom.2008.03.138 27. Alleg S, Bentayeb FZ, Bensalem R, Djebbari Ch, Bessais L, Greneche JM (2008) Effect of the milling conditions on the formation of nanostructured $\mathrm{Fe}-\mathrm{Co}$ powders. Phys.StatusSolidi A. 205: 1641 1646. https://doi.10.1002/pssa.200824040 
28. Bacmann M, Soubeyroux JL, Barrett R, Fruchart D, Zach R, Niziol S, Fruchart $R$ (1994) Magnetoelastic transition and antiferro-ferromagnetic ordering in the system $\mathrm{MnFeP}_{1-\mathrm{y}} \mathrm{As}_{\mathrm{y}}$. J. Magn.Magn Mater. 134:59-67.

https://doi.org/10.1016/0304-

8853(94)90073-6.

29. Broddefalk A, James P, Liu HP, Kalska B, Andersson Y, Granberg P, Nordblad P, Häggström L, Eriksson $\mathrm{O}$ (2000) Structural and magnetic properties of $\left(\mathrm{Fe}_{1-\mathrm{x}} \mathrm{Mn}_{\mathrm{x}}\right)_{3} \mathrm{P} \quad(\mathrm{x}<0.25)$. Phys. Rev. B. 61:

413-421.

https://doi.org/10.1103/PhysRevB.61.413.

30. Silva DCC, Crosnier O, Ouvrard G, Greedan J, Safa-Sefat A, Nazar LF (2003) Reversible lithium uptake by $\mathrm{FeP}_{2}$. Electrochem.Solid-StateLett.

6:A162-A165.

https://doi.10.1149/1.1588112.

31. Tang J, Zhang Zh, Lu B, Hao J, Yang $\mathrm{W}$ (2014) FeP nanoparticles grown on graphene sheets as highly active nonPrecious-metal electrocatalyst for hydrogen evolution reaction. Chem. Commun. 50:11554-11557. https://doi.10.1039/C4CC05285D.

32. Oyama ST, Gott T, Zhao H, Lee YK (2009) Transition metal phosphide hydroprocessing catalysts: A Review. Catal. Today. 143:94-107. https://doi.org/10.1016/j.cattod.2008.09.01 9

33. Han MY, Ye E, Zhang ShY, Lim SH, Bosman M, Zhang Zh, Win KhY (2011) Ternary cobalt-iron phosphide nanocrystals with controlled compositions, properties, and morphologies from nanorods and nanorice to split nanostructures. Chem. Eur. J. 17:59825988.

https://doi.org/10.1002/chem.201002698
34. Wei J, Feng E, Hao L, Cao D, Wang J, Liu Q (2013) The influence of magnetic heat treatment on morphology, structure, magnetic properties of Fe-Co-P alloy films. Appl. Phys. A. 115:359-363. https://doi.10.1007/s00339-013-7840-y.

35. Huang GF, Huang WQ, Liang B, Xie ChL (2009) Magnetic properties of CoFeP films prepared by electroless deposition. J. Magn. Magn. Mater. 321:1177-1181, https://doi.10.1016/j.jmmm.2008.10.028.

36. Liu HP, James P, Broddefalk A, Andersson Y, Granberg P, Eriksson O (1998) Structural and magnetic properties of $\left(\mathrm{Fe}_{1-\mathrm{x}} \mathrm{Co}_{\mathrm{x}}\right)_{3} \mathrm{P}$ compounds: Experiment and theory. J. Magn. Magn. Mater. 189:69-82. https://doi.10.1016/S03048853(98)00203-0

37. Mendoza-Garcia A, Zh H, Yu Y, Li Q, Zhou L, Su D, Kramer MJ, Sun Sh (2015) Controlled anisotropic growth of Co-Fe-P from $\mathrm{Co}-\mathrm{Fe}-\mathrm{O}$ nanoparticles. Angew.Chem.Int. Ed. 54:9642-9645. https://doi. org/10.1002/anie.201503386 38. Chen J, Liuc J, Xie JQ, Ye H, Fu XZh, Sun R, Wonge ChP (2018) Co-Fe-P nanotubes electrocatalysts derived from metal-organic frameworks for efficient hydrogen evolution reaction under wide pH range. Nano Energy. 56:225-233. https://doi.10.1016/j.nanoen.2018.11.051 39. Li D, Arachchige MP, Kulikowski B, Lawes G, Seda T, Brock SL (2016) Control of composition and size in discrete $\mathrm{Co}_{\mathrm{x}} \mathrm{Fe}_{2-\mathrm{x}} \mathrm{P}$ nanoparticles: Consequences for magnetic properties. Chem. Mater. 28:3920-2937.

https://doi.org/10.1021/acs.chemmater.6b0 1185.

40. Sun K, Wang K, Yu T, Liu X, Wang G, Jiang L, Bu Y, Xei G (2018) Highperformance $\mathrm{Fe}-\mathrm{Co}-\mathrm{P}$ alloy catalysts by electroless deposition for overall water splitting. Int. J. Hydrogen Energy.2018, 
44, 1328-1335.

https://doi.10.1016/j.ijhydene.2018.11.182 41. Wegliński B, Kaczmar J (1980) Effect of $\mathrm{Fe}_{3} \mathrm{P}$ addition on magnetic properties and structure of sintered iron. Powder Metall.

23:210-216. https://doi.10.1179/pom.1980.23.4.210

42. Moyer KH (1998) ASM Hand book. Powder metallurgy and application; magnetic materials and properties for part applications. 7:1006-1019.

43. Young RA (1996) The Rietveld method, 1st Ed., Oxford University, Oxford.

44. Lutterotti L, Matthies S, Wenk HR (1999) MAUD: A friendly java program for material analysis using diffraction. IUCr News letter of the CPD. 21:14-15.

45. Young RA (1993) The Rietveld method, Oxford University Press, Oxford.

46. SenGupta SP, Chatterjee P (2002) Powder diffraction: Proceedings of the II internation powder diffraction: Proceedings of the II international school on powder diffraction. Alliedpublishers LTD, India. 63-76.

47. Gravereau P (2012) Introduction à la pratique de la diffraction des rayons $\mathrm{X}$ par les poudres. ICMCB-CNRS, Université Bordeaux 1.

48. Hull D, Bacon D (1950) J. Introduction to Dislocations, fourth ed. Pergamon press, Oxford.

49. Warren BH, Averbach, B. L (1950) J. Appl. Phy. 21595.

50. Wareen BH (1969) X-Ray Diffraction. Addition-Wesley. 275.

51. Stibitz GR (1937). Phys. Rev. 49. 862 52. Easton SN, Küpper D, Ionescu A, Kurebayashi H, Barnes CHW (2010) Spinengineering in the $\mathrm{Co}_{75} \mathrm{Fe}_{25} / \mathrm{Cu}$ (110) system. J. Magn. Magn. 322:2493-2497. https://doi.org/10.1016/j.jmmm.2010.03.0 07
53. Joshua YJ, Bengtson AK, Ji CX, Morgan D, Chang YA (2008) Crystal structure effect of ferromagnetic electrode on tunneling magnetoresistance. Acta Mater. 56:1491-1495 https://doi.10.1016/j.actamat.2007.11.045 54. Gale B (1959) Lattice parameters of solid solutions of phosphorus in iron. Acta Metall. 7:420-421. https://doi. org/10.1016/0001-6160(59)90053-7.

55. Tebib W, Alleg S, Bensalem R, Bensebaa N, Bentayeb FZ, Suñol JJ, Grenèche JM (2008) Structural characterization of nanostructured $\mathrm{Fe}-8 \mathrm{P}$ powder mixture. J. Nanosci Nanotechnol. 8:2029-2036. https://doi.10.1166/jnn.2008.056.

56. Tebib, W.; Alleg, S.; Grenèche, J. M.; Suñol, J. J.Thermal Stability of the Nanocrystalline Fe-8P (wt. \%) Powder Produced by Ball Milling. Phosphorus, Sulfur Silicon Relat. Elem. 2018,193, 500506.

https://doi.org/10.1080/10426507.2018.14 52233.

57. Zhang M, Zhou P, Li Q, Gong P, Wang X (2020) Electrodeposition of FeCoP nanoglass films. Microelectron. Eng. 229:111363. https://doi.org/10.1016/j.mee.2020.111363 58. Vladyslav AV, James OR, Mark TK (2004) Structure, stress, and magnetic properties of high saturation magnetization films of FeCo. IEEE T MAGN. 40:23352337.

https://doi.10.1109/TMAG.2004.832256 59. Albaaji AJ, Castle EG, Reece MJ, Hall JP, Evans SL (2017) Effect of ballmilling time on mechanical and magnetic properties of carbon nanotube reinforced FeCo alloy composites. Mater.Des. 122:296-306.

https://doi.10.1016/j.matdes.2017.02.091 
60. Shokrollahi H, Janghorban K (2006) The effect of compaction parameters and particle size on magnetic properties of iron-based alloys used in soft magnetic composites. MSEB. 134:41-43. https://doi.10.1016/j.mseb.2006.07.015

61. Herzer G (1997) Handbook of magnetic materials; nanocrystalline soft magnetic materials. 10:415-462. https://doi. org/10.1016/S15672719(97)10007-5

62. Stoner EC, Wohlfarth EPA (1948) Mechanism of magnetic hysteresis in heterogeneous alloys.Soc. Lond.A. 240:599-642.

https://doi.org/10.1098/rsta.1948.0007.

63. Naganuma $\mathrm{H}$, Oogane $\mathrm{M}$, Ando $\mathrm{Y}$ (2011) Exchange biases of Co, Py, $\mathrm{Co}_{40} \mathrm{Fe}_{40} \mathrm{~B}_{20}, \mathrm{Co}_{75} \mathrm{Fe}_{25}$, and $\mathrm{Co}_{50} \mathrm{Fe}_{50}$ on epitaxial $\mathrm{BiFeO}_{3}$ films prepared by chemical solution deposition. Int. J. Appl. Phys. 109:07D736-1. https://doi.10.1063/1.3563061

64. Hamzaoui R, Elkedim O, Gaffet E, Greneche JM (2006) Structure, magnetic and Mössbauer studies of mechanically alloyed Fe-20 wt.\% Ni powders. J. Alloys Compd. 417:32-38. https://doi.org/10.1016/j.jallcom.2005.09.0 64

65. Shokrollahi H (2009) The magnetic and structural properties of the most important alloys of iron produced by mechanical alloying. Mater. Des. 30:33743387. https://doi. org/10.1016/j.matdes.2009.03.035

66. Kordecki A, Węgliński B, Kaczmar J (1982) Properties and applications of soft magnetic powder composites. Powder Metall. 25(4):201-208. https://doi.10.1179/ pom.1982.25.4.201
67. Manna SK, Prabhu DB, Gopalan R, Srinivas V (2014) AC magnetic properties and core loss behavior of Fe-P soft magnetic sheets. IEEE Trans. Magn. 50(11):4-7.

https://doi.10.1109/TMAG.2014.2331084 


\section{Figure Captions}

Fig. 1 XRD refined patterns with a zoom on sub-spectra of $\mathrm{CO}_{75} \mathrm{Fe}_{25}$ and $\alpha-\mathrm{Fe}(\mathrm{P})$ phases in the $\mathrm{Fe}_{15} \mathrm{Co}_{2} \mathrm{P}_{3}$ compound. (a) Un-milled and (b, c, d) milled for 1, 2 and $3 \mathrm{~h}$, respectively

Fig. 2 Evolution of (a) relative deviation of the lattice volume $\Delta \mathrm{V} / \mathrm{V}_{0}$; (b) phase composition; (c) antiphrases' presence probability; (d) stacking fault probability SFP; (e) dislocation density $\rho$; (f) crystallite size $\langle\mathrm{L}\rangle$ and (g) microstrain rate $\left\langle\sigma^{2}\right\rangle^{1 / 2}$, of the $\mathrm{Co}_{75} \mathrm{Fe}_{25}$ phase and $\alpha$ $\mathrm{Fe}(\mathrm{P})$ solid solution in the $\mathrm{Fe}_{15} \mathrm{Co}_{2} \mathrm{P}_{3}$ powder mixture during the milling

Fig. 3 Evolution with milling time of (a) Poisson ratio and (b) stored energy $E_{s}$ of $\mathrm{CO}_{75} \mathrm{Fe}_{25}$ phase and $\alpha-\mathrm{Fe}(\mathrm{P})$ solid solution in the $\mathrm{Fe}_{15} \mathrm{Co}_{2} \mathrm{P}_{3}$ powder mixture with milling time

Fig. 4 (a) Magnetization-field hysteresis loops; (b) hysteresis energy loss; (c) average coercive field $H_{C}$ and the nucleation field $H_{n}$ with the average grain size; (d) squareness ratio $\mathrm{M}_{\mathrm{r}} / \mathrm{M}_{\mathrm{s}}$; (e) switching field distribution $S F D$; and (f) maximum magnetic permeability of the $\mathrm{Fe}_{15} \mathrm{Co}_{2} \mathrm{P}_{3}$ powder mixture with milling time 
Figures
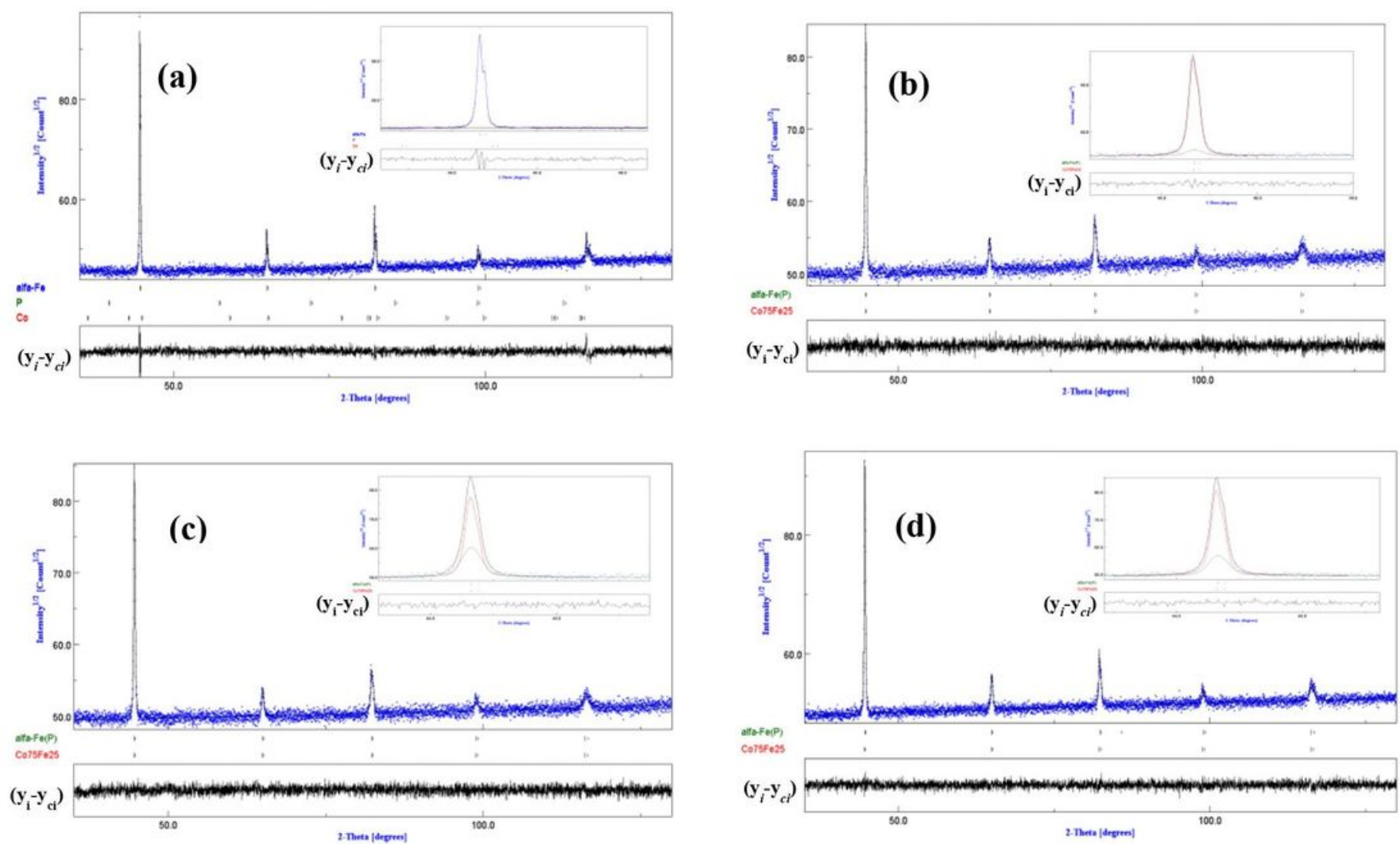

Figure 1

\section{Figure 1}

XRD refined patterns with a zoom on sub-spectra of Co75Fe25 and a-Fe(P) phases in the Fe15Co2P3 compound. (a) Un-milled and (b, c, d) milled for 1, 2 and 3 h, respectively 

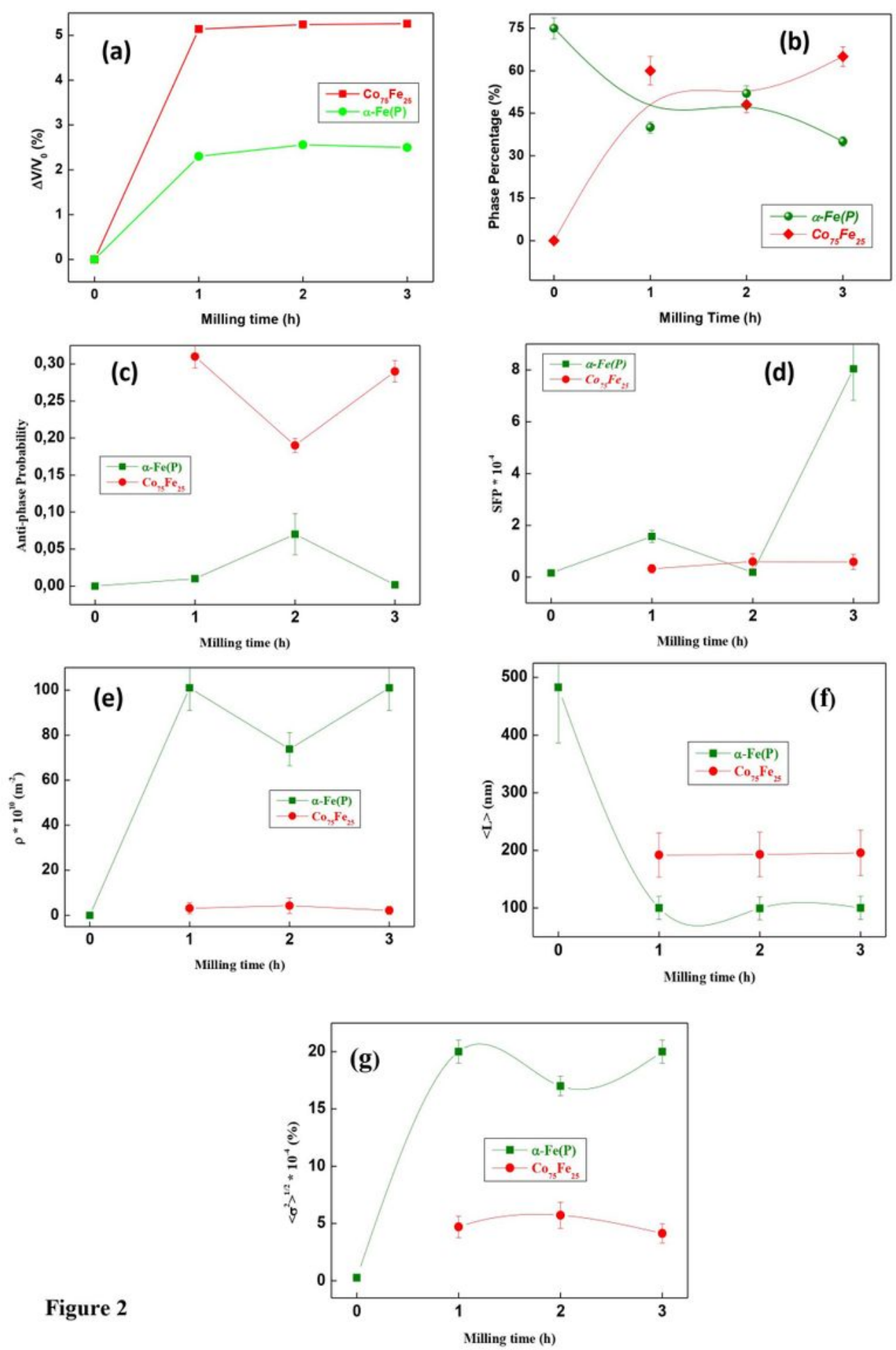

Figure 2

Figure 2

Evolution of (a) relative deviation of the lattice volume $\Delta \mathrm{V} / \mathrm{VO}$; (b) phase composition; (c) antiphrases' presence probability; (d) stacking fault probability SFP; (e) dislocation density $\rho$; (f) crystallite size $<L>$ and $(\mathrm{g})$ microstrain rate $<\sigma 2>1 / 2$, of the $\mathrm{Co} 75 \mathrm{Fe} 25$ phase and $\mathrm{a}-\mathrm{Fe}(\mathrm{P})$ solid solution in the $\mathrm{Fe} 15 \mathrm{Co} 2 \mathrm{P} 3$ powder mixture during the milling 

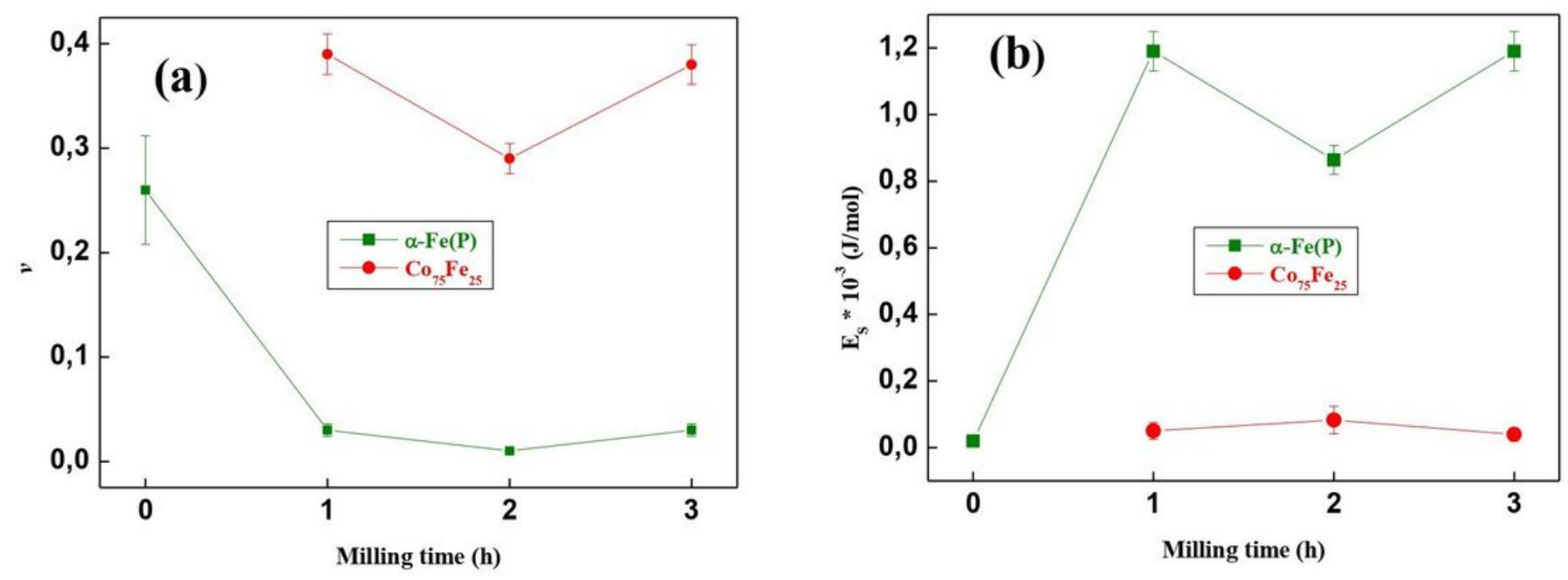

Figure 3

Figure 3

Evolution with milling time of (a) Poisson ratio and (b) stored energy Es of Co75Fe25 phase and a-Fe(P) solid solution in the Fe15Co2P3 powder mixture with milling time 

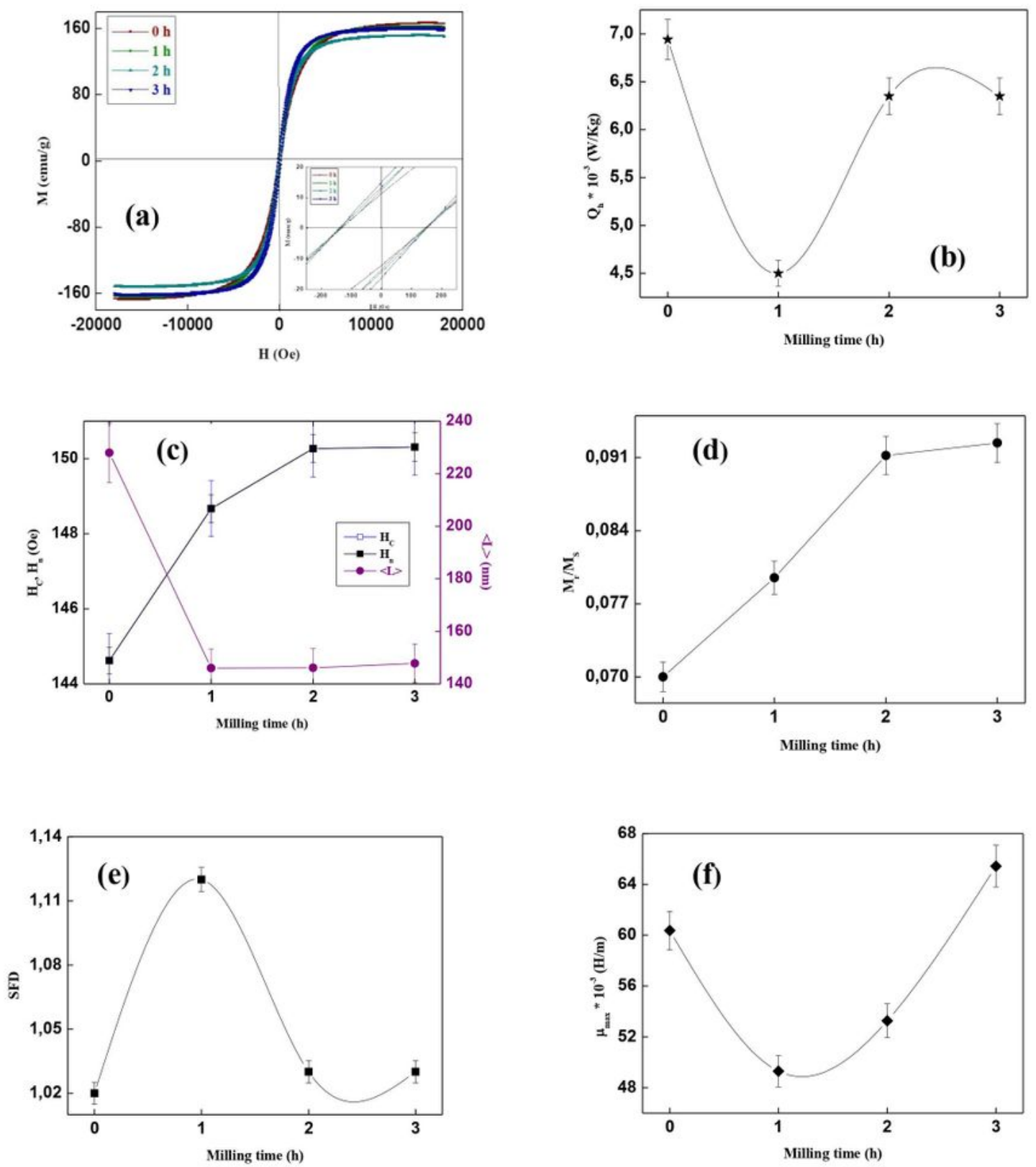

Figure 4

\section{Figure 4}

(a) Magnetization-field hysteresis loops; (b) hysteresis energy loss; (c) average coercive field HC and the nucleation field $\mathrm{Hn}$ with the average grain size; (d) squareness ratio Mr/Ms; (e) switching field distribution SFD; and (f) maximum magnetic permeability of the Fe15Co2P3 powder mixture with milling time 